\title{
Can sonographic features of microcalcification predict thyroid nodule malignancy? a prospective observational study
}

Mehrdad Nabahati ${ }^{1}$, Rahele Mehraeen ${ }^{2 *}$, Zoleika Moazezi ${ }^{3}$ and Naser Ghaemian ${ }^{1}$

\begin{abstract}
Background: The aim of this study was to investigate the diagnostic accuracy of microcalcification, as well as its associated sonographic features, for prediction of thyroid nodule malignancy.

We prospectively assessed the patients with thyroid nodule, who underwent ultrasound-guided fine-needle aspiration during 2017-2020 in Babol, northern Iran. The ultrasonographic characteristics of the nodules, as well as their cytological results, were recorded. We used regression analysis to evaluate the relation between sonographic findings and nodule malignancy. A receiver operator characteristics (ROC) analysis was also used to estimate the ability of ultrasound to predict the characteristic features of malignancy, as estimated by the area under the curve (AUC).

Results: Overall, 1129 thyroid nodules were finally included in the study, of which 452 (40\%) had microcalcification. A significant positive association was found between nodule malignancy and microcalcification in both univariate $(\mathrm{OR}=3.626,95 \% \mathrm{Cl}$ 2.258-5.822) and multivariable regression analyses $(\mathrm{OR}=1.878,95 \% \mathrm{Cl} 1.095-3.219)$. In the nodules with microcalcification, significant positive relations were seen between malignancy and hypoechogenicity $(\mathrm{OR}=3.833,95 \% \mathrm{Cl} 1.032-14.238)$, >5 microcalcification number $(\mathrm{OR}=3.045,95 \% \mathrm{Cl} 1.328-6.982)$, irregular margin $(\mathrm{OR}=3.341,95 \% \mathrm{Cl} 1.078-10.352)$, and lobulated margin (OR=5.727, 95\% Cl 1.934-16.959). The ROC analysis indicated that AUC for hypoechogenicity, $>5$ microcalcification number, irregular margin, and lobulated margin were 60\%,62\%, 55\%, and 60\%, respectively, in predicting malignant thyroid nodules.

Conclusion: The findings indicated that microcalcification can be a potential predictor of thyroid nodule malignancy. Also, the presence of irregular or lobulated margins, multiple intranodular microcalcification ( $>5$ microcalcifications), and/or hypoechogenicity can improve the ability of microcalcification in distinguishing malignant from benign nodules.
\end{abstract}

Keywords: Thyroid nodule, Ultrasonography, Microcalcification, Fine-needle aspiration

\footnotetext{
* Correspondence: rahelemehraeen4@gmail.com

${ }^{2}$ Department of Radiology, Rohani Hospital, Babol University of Medical

Sciences, Ganjafrooz Street, Babol, Mazandaran 47176-47745, Iran

Full list of author information is available at the end of the article
}

\section{Springer Open}

(c) The Author(s). 2021 Open Access This article is licensed under a Creative Commons Attribution 4.0 International License, which permits use, sharing, adaptation, distribution and reproduction in any medium or format, as long as you give appropriate credit to the original author(s) and the source, provide a link to the Creative Commons licence, and indicate if changes were made. The images or other third party material in this article are included in the article's Creative Commons licence, unless indicated otherwise in a credit line to the material. If material is not included in the article's Creative Commons licence and your intended use is not permitted by statutory regulation or exceeds the permitted use, you will need to obtain permission directly from the copyright holder. To view a copy of this licence, visit http://creativecommons.org/licenses/by/4.0/. 


\section{Background}

Thyroid cancer is one of the most common malignancies worldwide and its incidence has increased over the recent years. It has been reported that 567,000 cases were newly diagnosed in 2018 around the world, accounting for $3.1 \%$ of all new cancer cases [1]. Meanwhile, the role of thyroid nodules is notable. Thyroid nodules are frequent among adult people and up to $15 \%$ of them could be malignant $[2,3]$. Thus, their clinical and paraclinical assessments are important.

Ultrasound is typically the first paraclinical method for thyroid nodule examination, helping in differentiation between malignant and benign nodules. According to the literature, sonographic features suggesting malignancy include hypoechogenicity, irregular margins, taller-than-wide shape, and microcalcification (or fine calcification) $[4,5]$. Among these, microcalcifications are highly potential for prediction of malignancy (especially for papillary thyroid carcinoma) and have been stated to be linked to extra-thyroid extension and metastasis [6, 7]. Different values have been reported for microcalcifications in the diagnosis of malignant thyroid nodules. The diagnostic sensitivity and specificity vary from 26 to $59 \%$ and 86 to $94 \%$, respectively, according to different studies [8]. Therefore, observation alone of microcalcifications on sonography would not have enough diagnostic performance and identifying their patterns and accompanying sonographic features would be helpful in better distinguishing malignant from benign nodules.

The purpose of the present study was firstly assessment of the diagnostic performance of microcalcification for predictions of thyroid nodule malignancy in our region. Secondly, we aimed to compare different sonographic features between benign and malignant lesions in the thyroid nodules with microcalcification.

\section{Methods}

\section{Locations and patients}

The present cross-sectional study was prospectively performed, from August 2017 to May 2020, on the patients with thyroid nodules consecutively referring to the clinics of Shahid Beheshti teaching hospital or to the private offices in Babol, northern Iran, for ultrasoundguided fine-needle aspiration (FNA). Thyroid nodules were diagnosed in the patients in a thyroid examination by an endocrinologist and/or during the thyroid sonography by a radiologist. The exclusion criteria were purely cystic nodules with no solid component, suspicious cytology results (atypia), and patients' unwillingness to undergo FNA.

\section{Ultrasound imaging and FNA}

The criteria for considering a nodule as suspicious for malignancy was based on the following sonographic features: hypoechogenicity, calcification, irregular/lobulated margins, and/or a taller-than wide shape. Microcalcification was also defined as small $(<1 \mathrm{~mm})$ punctate echogenic foci without acoustic shadowing or a comet tail. The FNA procedure was conducted by a senior radiologist with an experience of more than 15 years. The thyroid nodules underwent ultrasound-guided FNA using a Samsung $\mathrm{H} 60$ ultrasound machine (3 to $14 \mathrm{MHz}$ linear array transducer) and a 23-gauge needle connected to a 5-cc syringe with the freehand procedure. The aspiration was performed from the solid area of the sample nodule for solid-cystic nodules.

\section{FNA cytology}

Following the aspiration, the sample was transmitted to the laboratory on smear glass slides after drying in the open air and fixation with 95\% alcohol. The Papanicolaou, Giemsa, and hematoxylin and eosin techniques were used to stain the fixed slides. To decrease the interobserver error, the identical interpretation, slide preparation technique, fixation and staining, and cytohistological examination of all specimens were conducted by an experienced pathologist who was blinded to the thyroid nodule sonographic diagnosis. Some samples were examined by two pathologists in difficult decision-making.

\section{Data collection}

The following data were collected from the patients undergoing ultrasound-guided FNA:

- Demographic information, including age and sex

- Ultrasonographic characteristics of the thyroid nodules, including the size of the nodule $(<2 \mathrm{~cm}$ or $>2 \mathrm{~cm}$ ), nodule calcification pattern (fine, coarse, fine-coarse, eggshell), intranodular microcalcification number $(>5$ or $<5$ ), nodule echogenicity (hyper, hypo, iso), the margins of the nodule (regular, irregular, ill defined, lobulated), and nodule composition (solid, solid-cystic)

- Cytological results

The data were recorded in a checklist form. Surgery was performed for the malignant thyroid nodules.

\section{Statistical analysis}

To analyze the data, SPSS software was used. Descriptive statistics were used to analyze the data. To statistically measure the diagnostic accuracy of microcalcification features, the contingency table values were defined as follows:

- True positive (TP): Thyroid nodule was determined to be malignant in both ultrasound and cytology. 
- True negative (TN): Thyroid nodule was established as benign in both ultrasound and cytology.

- False positive (FP): Ultrasonography was suggestive of malignancy but cytopathology was inconsistent.

- False negative (FN): Ultrasonography did not show malignancy but cytology suggested it.

Sensitivity was calculated as $\mathrm{TP} / \mathrm{TP}+\mathrm{FN}$, specificity as $\mathrm{TN} / \mathrm{TN}+\mathrm{FP}$, positive predictive value (PPV) as TP/TP+ $\mathrm{FP}$, negative predictive value (NPV) as $\mathrm{TN} / \mathrm{TN}+\mathrm{FN}$, and accuracy as proportion of TP+TN in all patients. The association between ultrasonographic features and malignancy was assessed using the logistic regression analysis. The data were presented as odds ratio (OR) as well as 95\% confidence interval (CI). A receiver operator characteristics (ROC) analysis was also used for estimating the ability of sonography to predict characteristic features of malignancy, as estimated by the area under the curve (AUC). A $p$-value less than 0.05 was considered as significant.

\section{Results}

In total, 1143 patients with thyroid nodules underwent ultrasound-guided FNA. Of whom, 1078 had single nodule and others had multiple nodules. Overall, 1228 thyroid nodules were initially assessed, of which 99 nodules were atypia according to cytopathology and were excluded from further investigation. A total of 1129 nodules (from 1039 patients) were finally included in the study. The number of female patients was 988 (86.4\%), and others were male. The mean age of the patients was $45.33 \pm 14.48$ years old. The mean size of the nodules was $1.74 \pm 1.04 \mathrm{~cm}$. The number of benign and malignant nodules was $998(88.4 \%)$ and 131 (11.6\%), respectively.

Out of 1129 nodules, 452 (40\%) had ultrasonic calcification. Table 1 represents the association between calcification patterns and cytology results of the thyroid nodules. As indicated, malignancy was observed in 25\% $(n=34)$ of the nodules with microcalcification. In this regard, a significant positive association was found between nodule malignancy and microcalcification in univariate logistic regression analysis $(\mathrm{OR}=3.626,95 \% \mathrm{CI}$ 2.258-5.822). This significant association was also seen after adjustment for echogenicity, margin, and solid/cystic component of the nodules $(\mathrm{OR}=1.878$, 95\% CI 1.095 3.219). The ROC analysis showed that AUC for microcalcification was $58 \%$ in predicting malignant thyroid nodules. The calculated sensitivity, specificity, PPV, NPV, and accuracy for microcalcification were $26 \%$, $89.8 \%, 25 \%, 93.2 \%$, and $82.4 \%$, respectively.

Out of 136 nodules with microcalcification, 102 (75\%) were benign and 34 (25\%) were malignant. The cytology findings proved that $70.6 \%$ of the nodules were nodular goiter, $23.5 \%$ were papillary thyroid carcinoma, $4.4 \%$ were thyroiditis, and $1.5 \%$ were follicular neoplasm. Table 2 shows the association between the cytology results (benign or malignant) and the sonographic features of the thyroid nodules with microcalcification. There were significant positive associations between malignancy and hypoechogenicity $(\mathrm{OR}=3.833$, 95\% CI 1.032 14.238), $>5$ microcalcification number $(\mathrm{OR}=3.045,95 \%$ CI 1.328-6.982), irregular margin (OR=3.341, 95\% CI $1.078-10.352)$, and lobulated margin $(\mathrm{OR}=5.727,95 \% \mathrm{CI}$ 1.934-16.959). The mean size between the benign and malignant nodules was $1.44 \pm 0.78$ and $1.27 \pm 0.65 \mathrm{~cm}$, respectively $(p=0.248)$. The ROC analysis indicated that AUC for hypoechogenicity, $>5$ microcalcifications, irregular margin, and lobulated margin were $60 \%, 62 \%$, $55 \%$, and $60 \%$, respectively, in predicting malignant thyroid nodules. The computed sensitivity, specificity, PPV, NPV, and accuracy for these sonographic features are also demonstrated in Table 3. Figures 1 and 2 also show the ultrasound-guided FNA of benign and malignant nodules.

\section{Discussion}

The results of the present study showed that microcalcification is directly associated with increased risk of thyroid nodule malignancy, which is in agreement with the existing data in the literature $[9,10]$. It was also found that the calculated sensitivity for the microcalcification was $26 \%$. In contrast, the specificity was as high as $89.8 \%$. The low sensitivity was not unexpected and could be explained by that the microcalcification is generally observed at a low rate on the thyroid nodule ultrasonography.

Table 1 Association between ultrasonic calcification patterns and cytology results of the thyroid nodules

\begin{tabular}{lllllll}
\hline Calcification pattern & Benign $(\boldsymbol{n}[\%])$ & Malignant $(\boldsymbol{n}[\%])$ & Crude OR $(\mathbf{9 5} \% \mathbf{C l})$ & $\boldsymbol{P}$-value & Adjusted OR $^{\mathbf{a}}\left(\mathbf{9 5} \% \mathrm{Cl}^{\prime}\right.$ & $\boldsymbol{P}_{\text {-value }}$ \\
\hline Negative & $623(93.4)$ & $44(6.6)$ & 1 & & 1 & \\
Microcalcification & $102(75)$ & $34(25)$ & $3.626(2.258-5.822)$ & $<0.001$ & $1.878(1.095-3.219)$ & 0.022 \\
Coarse & $97(89.8)$ & $11(10.2)$ & $1.233(0.625-2.435)$ & 0.545 & $0.898(0.429-1.878)$ & 0.775 \\
Fine-coarse & $114(89.1)$ & $14(10.9)$ & $1.554(0.861-2.803)$ & 0.143 & $1.704(0.916-3.170)$ & 0.093 \\
Eggshell & $77(85.6)$ & $13(14.4)$ & $2.111(1.098-4.055)$ & 0.025 & $1.290(0.635-2.619)$ & 0.481 \\
\hline
\end{tabular}

$O R$ odds ratio, $C l$ confidence interval

${ }^{a}$ Adjusted for echogenicity, margin and component of the nodules 
Table 2 Association between sonographic characteristics and cytology results of the thyroid nodules with microcalcification

\begin{tabular}{|c|c|c|c|c|}
\hline Sonographic features & Benign ( $n[\%])$ & Malignant ( $n$ [\%]) & $P$-value & Odds ratio ( $95 \%$ confidence interval) \\
\hline \multicolumn{5}{|l|}{ Nodule size $(\mathrm{cm})$} \\
\hline$<2$ & $85(73.3)$ & $31(26.7)$ & & 1 \\
\hline$\geq 2$ & $17(85)$ & $3(15)$ & 0.263 & $0.484(0.133-1.766)$ \\
\hline \multicolumn{5}{|c|}{ Microcalcification number } \\
\hline$<5$ & $81(81)$ & $19(19)$ & & 1 \\
\hline$>5$ & $21(58.3)$ & $15(41.7)$ & 0.007 & $3.045(1.328-6.982)$ \\
\hline \multicolumn{5}{|l|}{ Echogenicity } \\
\hline Hyperechogenicity & $23(88.5)$ & $3(11.5)$ & & 1 \\
\hline Isoechogenicity & $37(78.7)$ & $10(21.3)$ & 0.305 & $2.072(0.515-8.329)$ \\
\hline Hypoechogenicity & $42(66.7)$ & $21(33.3)$ & 0.045 & $3.833(1.032-14.238)$ \\
\hline \multicolumn{5}{|l|}{ Composition } \\
\hline Solid-cystic & $29(76.3)$ & $9(23.7)$ & & 1 \\
\hline Solid & $73(74.5)$ & $25(25.5)$ & 0.825 & $0.906(0.378-2.174)$ \\
\hline \multicolumn{5}{|l|}{ Margin } \\
\hline Regular & $63(85.1)$ & $11(14.9)$ & & 1 \\
\hline Irregular & $12(63.2)$ & $7(36.8)$ & 0.037 & 3.341 (1.078-10.352) \\
\hline III defined & $17(73.9)$ & $6(26.1)$ & 0.222 & $2.021(0.653-6.256)$ \\
\hline Lobulated & $10(50)$ & $10(50)$ & 0.002 & 5.727 (1.934-16.959) \\
\hline
\end{tabular}

We also tried to find out whether accompanying microcalcification by coarse calcification affects the diagnostic accuracy of microcalcification alone. In this regard, our analyses did not indicate a significant association between fine-coarse calcification and nodule malignancy, contrary to microcalcification alone. This finding is similar to our previously published data [11]. In other words, it seems that simultaneous presence of coarse calcification will probably decrease the diagnostic value of microcalcification for predicting malignancy. According to the literature, the association of malignancy with coarse calcification has remained debatable, especially in nodules lacking other malignant features $[12,13]$. Our finding is notable in terms of the American College of Radiology (ACR) Thyroid Imaging Reporting and Data System (TI-RADS). Based on ACR TI-RADS, when different calcification types are simultaneously observed on sonography, the score of each echogenic foci type should be summed to yield an overall calcification score [14], while our results do not support this approach. Altogether, more surveys need to be carried out to clearly determine the accuracy of simultaneous presence of coarse and microcalcification in predicting malignant thyroid nodules.

As results demonstrated, irregular and lobulated margins (but not regular margin) were identified as ultrasonographic features suggesting malignancy in the nodules with microcalcification. Recently, a study by Siebert et al. [15] concluded that jagged edges and lobulated margin could be considered as predictors of papillary thyroid carcinoma. Overall, the information on the association between different margin types and cancer risk in the nodules with microcalcification is limited and more studies are needed.

In this study, no diagnostic value was identified for the composition stratification of the nodules with microcalcification. According to the recent studies, a variable rate of thyroid cancer has been seen in both cystic and solid

Table 3 Diagnostic value of sonographic features in predicting malignancy for the thyroid nodules with microcalcification

\begin{tabular}{|c|c|c|c|c|c|}
\hline Ultrasound features & $\begin{array}{l}\text { Sensitivity (\%, } \\
95 \% \mathrm{Cl})\end{array}$ & $\begin{array}{l}\text { Specificity }(\%, \\
95 \% \mathrm{Cl})\end{array}$ & $\begin{array}{l}\text { Positive predictive value } \\
(\%, 95 \% \mathrm{Cl})\end{array}$ & $\begin{array}{l}\text { Negative predictive value } \\
(\%, 95 \% \mathrm{Cl})\end{array}$ & $\begin{array}{l}\text { Accuracy }(\%, \\
95 \% \mathrm{Cl})\end{array}$ \\
\hline Irregular margin & $6.9(2.8-13.6)$ & $64.7(46.5-82.3)$ & $36.8(20-57.7)$ & $18.8(15.2-23)$ & $21.3(14.8-29.2$ \\
\hline Lobulated margin & $9.8(4.8-17.3)$ & $70.6(52.5-84.9)$ & $50(31.3-68.7)$ & $20.7(17.2-24.7)$ & $25(18-33.1)$ \\
\hline Hypoechogenicity & $61.8(43.6-77.8)$ & $58.8(48.6-68.5)$ & $33.3(26-41.6)$ & $82.2(74.5-87.9)$ & $59.6(50.8-67.9$ \\
\hline $\begin{array}{l}>5 \text { microcalcification } \\
\text { number }\end{array}$ & $44.1(27.2-62.1)$ & $79.4(70.3-86.8)$ & $41.7(29.5-55)$ & $81(75.7-85.4)$ & $70.6(62.2-78.1)$ \\
\hline
\end{tabular}




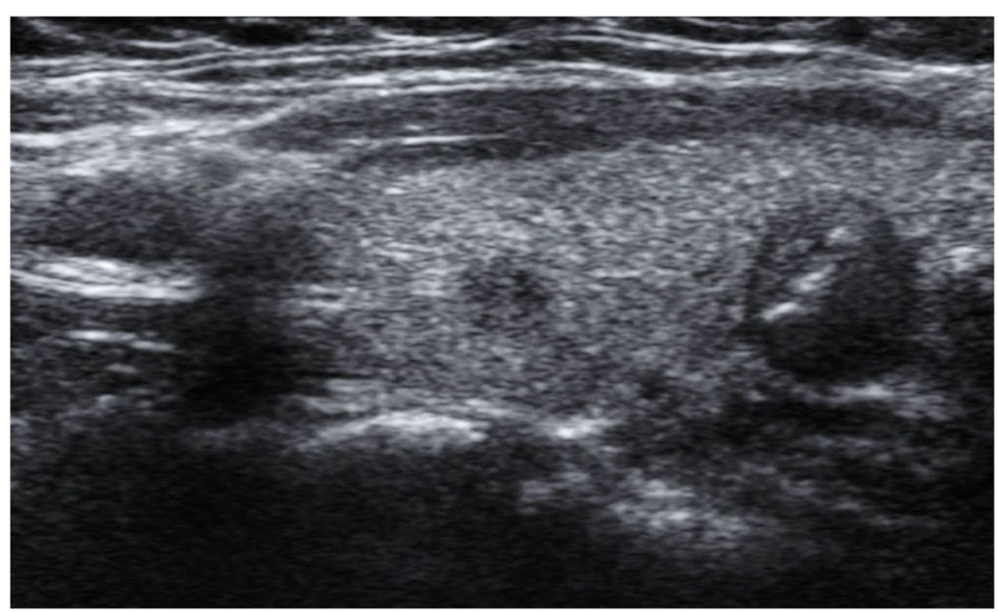

Fig. 1 The ultrasound-guided fine-needle aspiration from a hypoechoic nodule with regular margin and less than 5 punctate echogenic foci in the left thyroid lobe of a 26 -year-old female patient, which was proved by cytology to be a nodular goiter

nodules (about 5-18\%) [16, 17]. Some studies declared that the cancer risk in solid nodules is higher than in cystic nodules. Moreover, simultaneous presence of microcalcification and predominantly solid component is associated with an about 3-fold increase in malignancy risk [17], which was inconsistent with our results. However, further investigations are necessary to make this association clear.

Our results indicated no significant relation between the nodule size and risk of malignancy. There is a controversy whether thyroid cancer risk rises with increasing nodule size $[18,19]$. It has also been mentioned that the impact of size on the nodule malignancy risk could be variable by histopathologic type of the thyroid cancers. For instance, some studies noted that larger nodules could be associated with higher risk of nonpapillary thyroid carcinoma [20,21]. In other words, larger nodule sizes can increase risk of malignancy in lowor intermediate-suspicion nodules, but not in highsuspicion nodules. However, more studies need to clarify this issue.

According to the present study, ultrasonographic hypoechogenicity could be potentially a predictor of malignancy in the nodules with microcalcification. Despite the conflicting findings, hypoechoic nodules have been reported to be at higher risk of malignancy compared with iso- or hyperechoic nodules in most of the studies [22]. In addition, it has been revealed that marked and/ or moderate hypoechogenicity have a higher malignancy risk than mild hypoechogenicity [23]. In a recent meta-

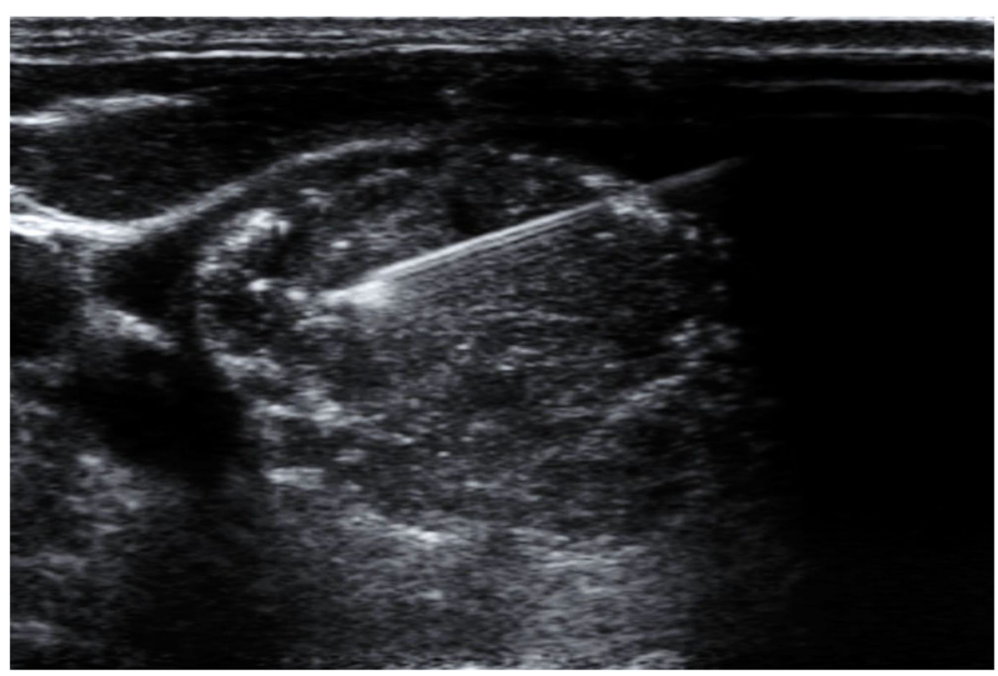

Fig. 2 The ultrasound-guided fine-needle aspiration from a hypoechoic solid nodule with more than 5 punctate echogenic foci in the right thyroid lobe of a 49-year-old female patient, which was proved by cytology to be a papillary thyroid carcinoma 
analysis by Remonti et al. [8], the sensitivity for hypoechogenicity was estimated to be $62.7 \%$ among unselected thyroid nodules.

In the present study, it was found that the thyroid nodules with $>5$ intranodular microcalcifications were at higher risk of malignancy compared with those with $<5$ microcalcifications. Theoretically, it might be assumed that multiple intranodular microcalcification is probably associated with higher risk of thyroid malignancy than single intranodular microcalcification. However, no sufficient evidence exists on this subject. In the study by Kobayashi et al. [24], the authors stated that multiple punctate echogenic foci ( $>5$ microcalcification number) were observed in all diffuse sclerosing variant of papillary carcinoma, but not in any follicular carcinoma lesions. Also, multiple punctate echogenic foci has been reported to be found in both benign and malignant thyroid nodules [24]. Thus, other sonographic features along with the cytopathological appearance should be assessed for a correct diagnosis of nodules with multiple punctate echogenic foci. Based on the present results, as a suggestion, the subcategory of "intranodular microcalcification number" could be added to the TI-RADS echogenic foci scoring, upon which the microcalcification number is directly correlated with echogenic foci score. Altogether, more surveys are needed to find out whether risk of malignancy increases with the number of intranodular microcalcification.

A limitation of our study was the lack of access to the results of repeat FNA in some patients with the atypia. Further, the pathological results of malignant thyroids of patients who underwent surgery were not collected. Therefore, we suggest designing new studies to compare the sonographic and FNA results with pathological findings. Moreover, multicenter studies with larger sample size are recommended to enable more generalizable results.

A strength of the present study is the prospective design versus the previous studies which were retrospective. Therefore, our results are potentially more comprehensive and precise compared with other studies due to various issues in data collection (e.g., more accurate data recording and less recall bias).

\section{Conclusion}

According to the present study, microcalcification on sonography can be a potential predictor of thyroid nodule malignancy. Also, the presence of irregular or lobulated margins, multiple intranodular microcalcification (>5 microcalcifications), and/or hypoechogenicity can improve the ability of microcalcification in distinguishing malignant from benign nodules. As a suggestion, the subcategory of "intranodular microcalcification number" could be added to the TI-RADS echogenic foci scoring, upon which the microcalcification number is directly correlated with echogenic foci score. Furthermore, our results did not show a significant association between fine-coarse calcification and nodule malignancy, contrary to microcalcification alone, suggesting that the score of each echogenic foci type probably should not be summed to yield an overall calcification score in TIRADS.

\section{Abbreviations \\ TI-RADS: Thyroid Imaging-Reporting and Data System; FNA: Fine-needle aspiration; TP: True positive; TN: True negative; FP: False positive; FN: False negative; PPV: Positive predictive value; NPV: Negative predictive value; ROC: Receiver operator characteristics; AUC: Area under the curve; OR: Odds ratio; Cl: Confidence interval}

\section{Acknowledgements}

We would like to thank the Vice Chancellor for Research and Technology of Babol University of Medical Sciences for supporting this study. We also thank Dr. Kourosh Movagharnejad for his help in pathological assessments.

\section{Authors' contributions}

$\mathrm{MN}$ and RM contributed in the study design. $\mathrm{MN}$ and $\mathrm{ZM}$ contributed in the data collection. MN, RM, and NG contributed in drafting the manuscript. All authors have read the manuscript and approved its final version.

Funding

Not applicable.

\section{Availability of data and materials}

The datasets during and/or analyzed during the current study are available from the corresponding author on reasonable request.

\section{Declarations}

\section{Ethics approval and consent to participate}

The details of this study were initially explained to the patients, and then, the written informed consents were taken from all of them. The study protocol was approved by the ethics committee of Babol University of Medical Sciences (code: IR.MUBABOL.REC.1399.223). The patients' information was kept confidential.

\section{Consent for publication}

The written informed consent was obtained from all research participants after a full explanation of the study.

\section{Competing interests}

The authors declare that they have no competing interests.

\section{Author details}

'Department of Radiology, Shahid Beheshti Hospital, Babol University of Medical Sciences, Babol, Iran. '2Department of Radiology, Rohani Hospital, Babol University of Medical Sciences, Ganjafrooz Street, Babol, Mazandaran 47176-47745, Iran. ${ }^{3}$ Department of Endocrinology, Rohani Hospital, Babol University of Medical Sciences, Babol, Iran.

Received: 25 February 2021 Accepted: 19 April 2021

Published online: 30 April 2021

References

1. Bray F, Ferlay J, Soerjomataram I, Siegel RL, Torre LA, Jemal A (2018) Global cancer statistics 2018: GLOBOCAN estimates of incidence and mortality worldwide for 36 cancers in 185 countries. CA Cancer J Clin 68(6):394-424. https://doi.org/10.3322/caac.21492

2. Popoveniuc G, Jonklaas J (2012) Thyroid nodules. Med Clin North Am 96(2): 329-349. https://doi.org/10.1016/.mcna.2012.02.002

3. Hoang J (2010) Thyroid nodules and evaluation of thyroid cancer risk. Australas J Ultrasound Med 13(4):33-36. https://doi.org/10.1002/.2205-014 0.2010.tb00177.x 
4. Pang Z, Margolis M, Menezes RJ, Maan H, Ghai S (2019) Diagnostic performance of 2015 American Thyroid Association guidelines and interobserver variability in assigning risk category. Eur J Radiol Open 6:122-127. https://doi.org/10.1016/j.ejro.2019.03.002

5. Song JSA, Dmytriw AA, Yu E, Forghani R, Rotstein L, Goldstein D, Poon CS (2018) Investigation of thyroid nodules: a practical algorithm and review of guidelines. Head Neck 40(8):1861-1873. https://doi.org/10.1002/hed.25160

6. Liu T, Zhou S, Yu J, Guo Y, Wang Y, Zhou J et al (2019) Prediction of lymph node metastasis in patients with papillary thyroid carcinoma: a radiomics method based on preoperative ultrasound images. Technol Cancer Res Treat 18:1533033819831713

7. Pyo J-S, Kang G, Kim D-H, Park C, Kim JH, Sohn JH (2013) The prognostic relevance of psammoma bodies and ultrasonographic intratumoral calcifications in papillary thyroid carcinoma. World J Surg 37(10):2330-2335. https://doi.org/10.1007/s00268-013-2107-5

8. Remonti LR, Kramer CK, Leitao CB, Pinto LCF, Gross JL (2015) Thyroid ultrasound features and risk of carcinoma: a systematic review and metaanalysis of observational studies. Thyroid 25(5):538-550. https://doi.org/10.1 089/thy.2014.0353

9. C-p N, Q-I J, S-b F, Wang H-q, Y-m Z, H-t N (2018) Distribution patterns of microcalcifications in suspected thyroid carcinoma: a classification method helpful for diagnosis. Eur Radiol 28(6):2612-2699

10. Liu J, Zheng D, Li Q, Tang X, Luo Z, Yuan Z, Gao L, Zhao J (2018) A predictive model of thyroid malignancy using clinical, biochemical and sonographic parameters for patients in a multi-center setting. BMC Endocr Disord 18(1):17. https://doi.org/10.1186/s12902-018-0241-7

11. Nabahati M, Moazezi Z, Fartookzadeh S, Mehraeen R, Ghaemian N, Sharbatdaran M (2019) The comparison of accuracy of ultrasonographic features versus ultrasound-guided fine-needle aspiration cytology in diagnosis of malignant thyroid nodules. J Ultrasound 2(3):315-321

12. Arpana OBP, Gurung G, Pradhan S (2018) Ultrasound findings in thyroid nodules: A radio-cytopathologic correlation. J Med Ultrasound 6(2):90-93

13. Saito D, Nakajima R, Yasuda S (2020) Examination of malignant findings of thyroid nodules using thyroid ultrasonography. J Clin Med Res 12(8):499507. https://doi.org/10.14740/jocmr4260

14. Tessler FN, Middleton WD, Grant EG, Hoang JK, Berland LL, Teefey SA et a (2017) ACR thyroid imaging, reporting and data system (TI-RADS): white paper of the ACR TI-RADS committee. J Am Coll Radiol 4(5):587-595

15. Siebert SM, Gomez AJ, Liang T, Tahvildari AM, Desser TS, Jeffrey RB, Kamaya A (2018) Diagnostic performance of margin features in thyroid nodules in prediction of malignancy. AJR Am J Roentgenol 210(4):860-865. https://doi. org/10.2214/AJR.17.18787

16. García-Pascual L, Barahona M-J, Balsells M, Del Pozo C, Anglada-Barceló J, Casalots-Casado J et al (2011) Complex thyroid nodules with nondiagnostic fine needle aspiration cytology: histopathologic outcomes and comparison of the cytologic variants (cystic vs. acellular). Endocrine 39(1):33-40. https:// doi.org/10.1007/s12020-010-9409-2

17. Li W, Zhu Q, Jiang Y, Zhang Q, Meng Z, Sun J, Li J, Dai Q (2017) Partially cystic thyroid nodules in ultrasound-guided fine needle aspiration: Prevalence of thyroid carcinoma and ultrasound features. Medicine (Baltimore) 96(46):e8689. https://doi.org/10.1097/MD.0000000000008689

18. Zhao L, Yan H, Pang P, Fan X, Jia X, Zang L, Luo Y, Wang F, Yang G, Gu W, du J, Wang X, Lyu Z, Dou J, Mu Y (2019) Thyroid nodule size calculated using ultrasound and gross pathology as predictors of cancer: a 23-year retrospective study. Diagn Cytopathol 47(3):187-193. https://doi.org/10.1 002/dc.24068

19. Al-Hakami HA, Alqahtani R, Alahmadi A, Almutairi D, Algarni M, Alandejani T (2020) Thyroid nodule size and prediction of cancer: a study at tertiary care hospital in Saudi Arabia. Cureus 12(3):e7478. https://doi.org/10.7759/cureus. 7478

20. Cavallo A, Johnson DN, White MG, Siddiqui S, Antic T, Mathew M, Grogan RH, Angelos P, Kaplan EL, Cipriani NA (2017) Thyroid nodule size at ultrasound as a predictor of malignancy and final pathologic size. Thyroid 27(5):641-650. https://doi.org/10.1089/thy.2016.0336

21. Hong MJ, Na DG, Baek JH, Sung JY, Kim J-H (2018) Impact of nodule size on malignancy risk differs according to the ultrasonography pattern of thyroid nodules. Korean J Radiol 19(3):534-541. https://doi.org/10.3348/kjr.2018.19.3.534

22. Brito JP, Gionfriddo MR, Al Nofal A, Boehmer KR, Leppin AL, Reading $C$ et al (2014) The accuracy of thyroid nodule ultrasound to predict thyroid cancer: systematic review and meta-analysis. J Clin Endocrinol Metab 99(4):12531263. https://doi.org/10.1210/jc.2013-2928
23. Lee JY, Na DG, Yoon SJ, Gwon HY, Paik W, Kim T, Kim JY (2020) Ultrasound malignancy risk stratification of thyroid nodules based on the degree of hypoechogenicity and echotexture. Eur Radiol 30(3):1653-1663. https://doi. org/10.1007/s00330-019-06527-8

24. Kobayashi K, Fujimoto T, Ota H, Hirokawa M, Yabuta T, Masuoka H, Fukushima M, Higashiyama T, Kihara M, Ito Y, Miya A, Miyauchi A (2018) Calcifications in thyroid tumors on ultrasonography: calcification types and relationship with histopathological type. Ultrasound Int Open 4(2):E45-E51. https://doi.org/10.1055/a-0591-6070

\section{Publisher's Note}

Springer Nature remains neutral with regard to jurisdictional claims in published maps and institutional affiliations.

\section{Submit your manuscript to a SpringerOpen ${ }^{\circ}$ journal and benefit from:}

- Convenient online submission

- Rigorous peer review

- Open access: articles freely available online

High visibility within the field

- Retaining the copyright to your article

Submit your next manuscript at $\boldsymbol{\nabla}$ springeropen.com 